\title{
Electrical Synapses in the Thalamic Reticular Nucleus
}

\author{
Carole E. Landisman, ${ }^{1}$ Michael A. Long, ${ }^{1}$ Michael Beierlein, ${ }^{1}$ Michael R. Deans, ${ }^{2}$ David L. Paul, ${ }^{2}$ and \\ Barry W. Connors ${ }^{1}$ \\ ${ }^{1}$ Department of Neuroscience, Division of Biology and Medicine, Brown University, Providence, Rhode Island 02912, and \\ 2Department of Neurobiology, Harvard Medical School, Boston, Massachusetts 02115
}

Neurons of the thalamic reticular nucleus (TRN) provide inhibitory input to thalamic relay cells and generate synchronized activity during sleep and seizures. It is widely assumed that TRN cells interact only via chemical synaptic connections. However, we show that many neighboring pairs of TRN neurons in rats and mice are electrically coupled. In paired-cell recordings, electrical synapses were able to mediate close correlations between action potentials when the coupling was strong; they could modulate burst-firing states even when the coupling strength was more modest. Electrical synapses between TRN neurons were absent in mice with a null mutation for the connexin36 (Cx36) gene. Surprisingly, inhibitory chemical syn- aptic connections between pairs of neurons were not observed, although strong extracellular stimuli could evoke inhibition in single TRN neurons. We conclude that Cx36-dependent gap junctions play an important role in the regulation of neural firing patterns within the TRN. When combined with recent observations from the cerebral cortex, our results imply that electrical synapses are a common mechanism for generating synchrony within networks of inhibitory neurons in the mammalian forebrain.

Key words: thalamus; reticular nucleus; gap junctions; electrical coupling; connexin36; rat; mouse; inhibition; synchrony
The thalamic reticular nucleus (TRN) is a thin layer of inhibitory neurons that borders relay nuclei of the dorsal thalamus (Steriade et al., 1997). Excitatory inputs to TRN neurons come from topographically aligned collaterals of both thalamocortical and corticothalamic axons. Neurons of the TRN are exclusively GABA containing (Houser et al., 1980; Spreafico et al., 1991), and the primary targets of inhibitory TRN axon terminals are the thalamic relay neurons (Ohara, 1988; Pinault and Deschenes, 1998). Thus, the anatomy of the TRN suggests that the bidirectional excitatory activity between the thalamus and the neocortex generates, in parallel, an inhibitory regulation of the relay neurons (Kim et al., 1997).

A wide range of functions has been proposed for the TRN; all of them depend on the nature of its intrinsic circuitry (Wang and Rinzel, 1993; Destexhe et al., 1994; Ulrich and Huguenard, 1996). Anatomical and physiological investigations of the TRN have concluded that its neurons interact via chemical synaptic connections (Ohara, 1988; Bal et al., 1995b; Ulrich and Huguenard, 1996; Sanchez-Vives et al., 1997; Huntsman et al., 1999; Sohal et al., 2000). Several studies describe local axon collaterals within the TRN (Scheibel and Scheibel, 1966; De Biasi et al., 1988; Cox et al., 1996; Liu and Jones, 1999); electron microscopy shows that these axons form axosomatic and axodendritic chemical synapses on TRN cells (Williamson et al., 1994; Liu and Jones, 1999). However, some analyses of the somatosensory thalamus in rats

\footnotetext{
Received Sept. 20, 2001; revised Nov. 8, 2001; accepted Nov. 9, 2001.

This work was supported by the Helen Hay Whitney Foundation (C.E.L.) and by the Burroughs-Wellcome Trust (M.B.). This work was also funded by National Institutes of Health Grants NS25983 and NS27248 to B.W.C. and GM37751 and GM18974 to D.L.P. We thank Jay Gibson for developing the data acquisition and analysis software and Saundy Patrick and Caterina Sellitto for excellent technical assistance.

Correspondence should be addressed to Barry W. Connors, Box 1953, Department of Neuroscience, Brown University, Providence, RI 02912. E-mail: bwc@brown.edu.

Copyright (ㄷ) 2002 Society for Neuroscience $\quad 0270-6474 / 02 / 221002-08 \$ 15.00 / 0$
}

suggest that intrinsic TRN axons are relatively sparse or absent (Pinault et al., 1995) and that TRN neurons interact through dendrodendritic (presumably GABAergic) synapses (Deschenes et al., 1985; Yen et al., 1985). Whatever their precise morphological substrate, there has been nearly universal agreement that GABA-mediated inhibitory synapses are the mechanism by which neurons within the TRN network interact (but see Warren et al., 1994).

There are also hints that TRN neurons may communicate using mechanisms other than GABAergic chemical synapses. The dendrites of TRN cells often bundle tightly together (Scheibel and Scheibel, 1966; Steriade et al., 1997), and puncta adherentia, which are small, specialized intercellular junctions, sometimes form at dendrodendritic appositions (Ohara and Lieberman, 1985; Pinault et al., 1997). Unfortunately, the functions of puncta adherentia are unknown.

Recent work on GABAergic neurons in the neocortex (Galarreta and Hestrin, 1999; Gibson et al., 1999) and several other parts of the mammalian brain (Galarreta and Hestrin, 2001) suggests that electrical coupling may be a common feature of networks of inhibitory neurons. Gap junctions are the ultrastructural substrate of electrical synapses (Bennett, 1977), and connexins are the proteins that comprise gap junction channels. In situ hybridization shows that the mRNA for connexin36 (Cx36) (Condorelli et al., 1998), a connexin subtype that is most often associated with neuronal gap junctions (Rash et al., 2000), is strongly expressed in the TRN (Condorelli et al., 2000). Here we show that $\mathrm{Cx} 36$-dependent electrical synapses exist in the TRN of rats and mice, and we describe their functional properties.

\section{MATERIALS AND METHODS}

Thalamocortical slices, 300- to $400-\mu \mathrm{m}$-thick, were prepared as described previously (Gibson et al., 1999) from either Sprague Dawley rats [postnatal day 14 (P14) to P21] or Cx36 wild-type (WT) or knockout (KO) littermate mice (P14-P18) and were constructed as described previously 
(Deans et al., 2001). Slices were visualized using either an Olympus Optical (Tokyo, Japan) BX50WI or a Zeiss (Oberkochen, Germany) Axioskop microscope and a Hamamatsu (Hamamatsu City, Japan) CCD camera using infrared-differential interference contrast (IR-DIC) in a submerged recording chamber at $32^{\circ} \mathrm{C}$. The bathing solution [artificial CSF (ACSF)] contained (in mM): $126 \mathrm{NaCl}, 3 \mathrm{KCl}, 1.25 \mathrm{NaH}_{2} \mathrm{PO}_{4}, 26$ $\mathrm{NaHCO}_{3}, 2 \mathrm{CaCl}_{2}, 10$ dextrose, and either 1 or $2 \mathrm{MgCl}_{2}$. Micropipettes were filled with (in mM): $130 \mathrm{~K}$-gluconate, 0.2 EGTA, $4 \mathrm{KCl}, 2 \mathrm{NaCl}, 10$ HEPES, 20 sucrose, 4 ATP-Mg, 0.3 GTP-Tris, and 14 phosphocreatineTris, $\mathrm{pH}$ 7.25-7.5, (280-293 mOsm). Recordings were performed in current clamp using Axoprobe amplifiers (Axon Instruments, Foster City, CA). In some cases, neurobiotin $(4 \mathrm{mg} / \mathrm{ml})$ was added to the electrode filling solution to test for dye coupling. The technique for developing the tissue has been described previously (Gibson et al., 1999).

Extracellular stimuli were delivered using bipolar stimulating electrodes, monopolar tungsten electrodes, and ACSF-filled glass electrodes. Data were collected and analyzed using a digital-to-analog board and Labview software (National Instruments, Austin, TX) on a personal computer (Dell Computer Company, Round Rock, TX). To test for the presence of chemical synapses, five spikes were elicited in each neuron of a pair at $40 \mathrm{~Hz}$ while observing the postsynaptic membrane potential at high gain. To estimate the strength of coupling, a small hyperpolarizing current step (600 msec duration) was injected into one cell while measuring the voltage deflection in that cell $\left(\Delta V_{1}\right)$ and the coupled cell $\left(\Delta V_{2}\right)$ (see Fig. $2 A$ ); the coupling coefficient was defined as $\Delta V_{2} / \Delta V_{1}$. The coupling coefficients for each cell are derived from the average of 10-20 trials obtained from current steps applied to each cell of a pair; they did not depend on which cell of each pair was stimulated. For estimates of the frequency dependence of coupling, resting membrane potentials were polarized to between -70 and $-80 \mathrm{mV}$ to prevent spiking, and sinusoidal currents were applied to one neuron $(1-100 \mathrm{~Hz}$, with amplitudes sufficient to generate peak-to-peak voltage deflections of $20-25 \mathrm{mV}$ in the injected cell).

\section{RESULTS}

\section{Electrical synapses between neurons in the TRN}

To test for the presence of electrical and chemical synapses, we recorded from pairs of TRN neurons in slices of rat or mouse thalamus. Recordings were made along the full extent of the nucleus (Fig. 1A). However, most recorded pairs were in the dorsal cap because its relatively low myelination allowed better visualization of somata. We did not detect any difference in the electrical coupling of cells recorded at different locations within the TRN. The intrinsic firing properties of TRN cells in both mice and rats were similar to previous descriptions (Steriade et al., 1997). The input resistance of the TRN neurons in rats was $166 \pm 54 \mathrm{M} \Omega$ (all reported data are means $\pm \mathrm{SD}$ ), and the time constant was $13.1 \pm 3.7 \mathrm{msec}(n=45)$. The properties of the mouse cells are reported below. Cell pairs were spaced $<35 \mu \mathrm{m}$ apart (Fig. 1B). Four TRN cells were injected with neurobiotin, and their morphology was reconstructed. In all cases, only a single stained neuron was recovered (Fig. 1C). Each cell had an ovoid soma and a long primary axon that emanated dorsolaterally and coursed for several hundred micrometers. The axons made very few collaterals within the TRN and traveled $0.5-1 \mathrm{~mm}$ into adjacent relay nuclei before branching extensively; in some cases, they formed terminal tufts.

The chemical synaptic connections between pairs of neurons were tested by evoking single or short trains of action potentials in one cell and measuring spike-triggered voltage changes in the other cell while depolarizing by $\sim 10-15 \mathrm{mV}$ to maximize the visibility of IPSPs. Surprisingly, no evidence of chemical synapses was observed (rats, $n=56$ pairs; mice, $n=34$ ). The absence of IPSPs was probably not attributable to the "washout" of postsynaptic receptor function, because we were able to evoke IPSPs by stimulating extracellularly within the nucleus (data not shown). As described in previous studies (Ulrich and Huguenard, 1996; Zhang et al., 1997; Huntsman et al., 1999), the current required
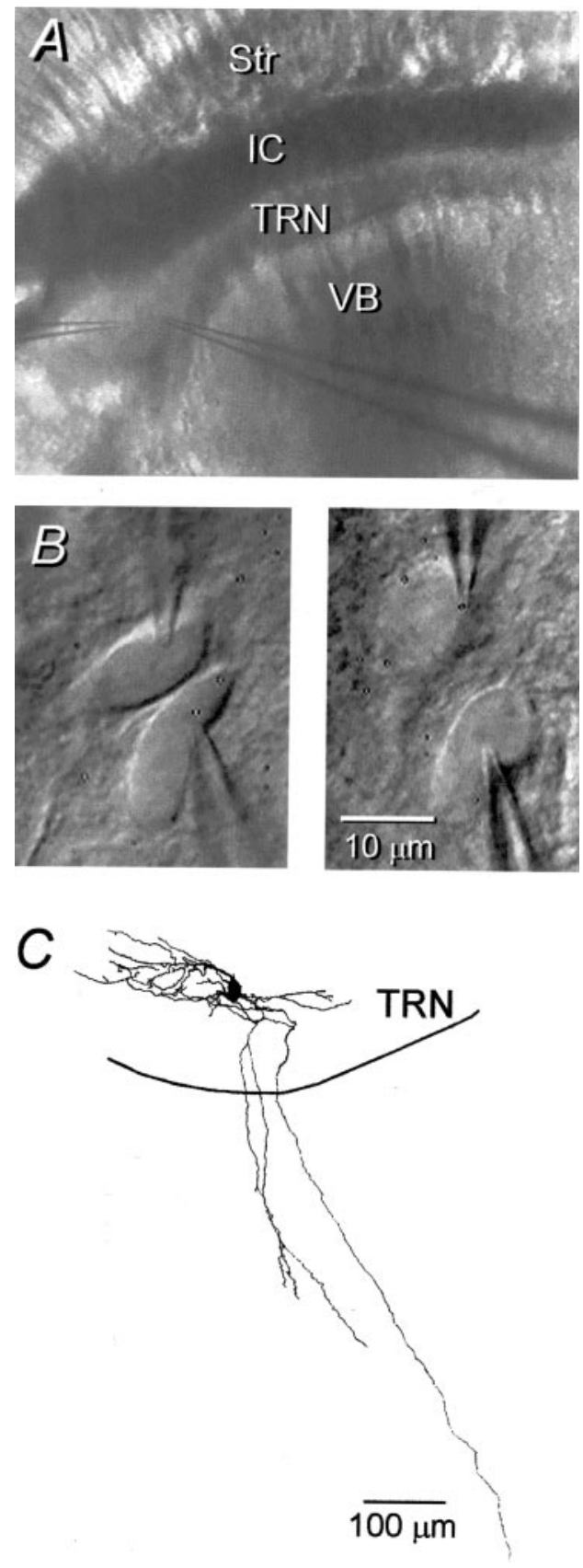

Figure 1. Structure of the TRN slice and its neurons. A, Low-power IR-DIC image of the thalamic region of a living slice. Str, Striatum; IC, internal capsule. $B$, Higher-power view of a pair of TRN cells with adjoining somata (left). This pair was not electrically coupled. The right shows a pair of TRN cells with nonadjoining somata. These cells were strongly coupled (coupling coefficient of 0.1 ). Thus, the somata of cell pairs need not touch to be electrically coupled, and many pairs that do have adjacent somata are not coupled. $C$, Reconstruction of a neurobiotin-filled TRN neuron. Three major axonal branches leave the nucleus.

to evoke even a minimal IPSP was quite high (400-500 $\mu \mathrm{A}$ evoked a $0.5 \mathrm{mV}$ IPSP at rest when stimulating 10-20 $\mu \mathrm{m}$ away), suggesting that chemical synaptic connections within the TRN are sparse (Ohara and Lieberman, 1985; Liu and Jones, 1999).

In contrast to chemical synapses, electrical synapses were commonly observed between pairs of TRN cells. Electrical connections were tested by applying current in steps of varying duration, 


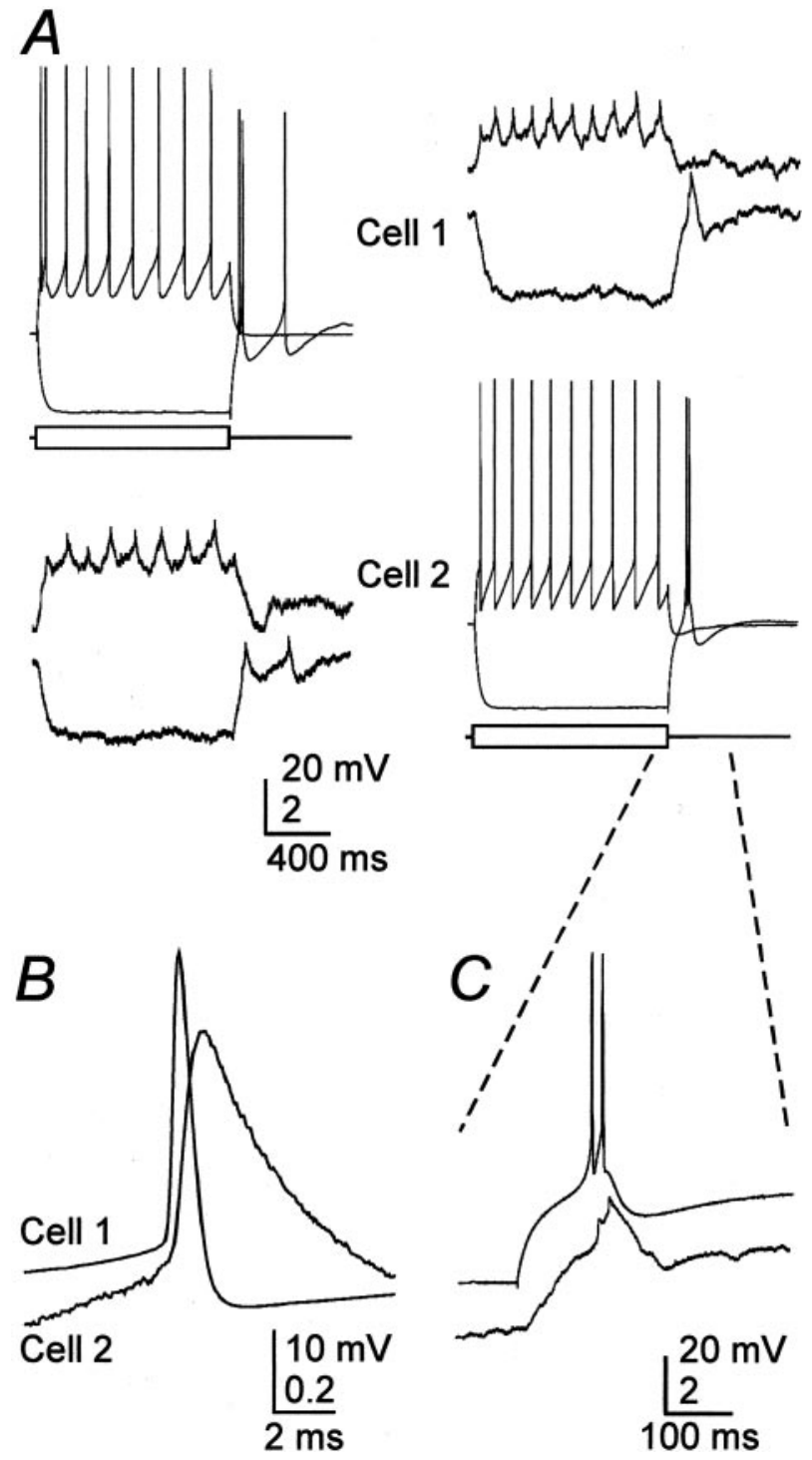

Figure 2. Electrical coupling between rat TRN neurons. $A$, Intracellular current steps $( \pm 200 \mathrm{pA})$ to evoke responses in cell 1 induced attenuated voltage changes in cell 2 (left traces) (coupling coefficient of 0.1 ). Tracings on the right are from the same cell pair, but, in this case, current steps were delivered to cell 2. $B$, Close-up of a single presynaptic spike and the averaged spikelet it induced in the soma of a coupled neighboring cell. $C$, Close-up of the rebound burst generated by cell 2 in $A$ (right) and the coupling potential corresponding to it in cell 1.

strength, and polarity to one cell while searching for appropriately timed and scaled voltage deflections in the second cell. Approximately 31\% (28 of 90) of paired neurons from the TRN of rats clearly showed electrical coupling (Fig. $2 A$ ). The strength of each electrical connection was quantified by calculating a coupling coefficient, which averaged $0.032 \pm 0.027$ (range, 0.01$0.13 ; n=28$ ) for low-frequency, or steady-state, voltage deflections. Electrical coupling was symmetric [signals passed equally well in both directions (Fig. $2 A$ )] and was independent of transjunctional voltage over a range of at least $\pm 20 \mathrm{mV}$.

Electrical synapses had strong low-pass filtering characteristics. Single action potentials generated a small but rapidly rising electrical postsynaptic potential in some electrically coupled cells, and such spikelets had an average rise time of $0.43 \mathrm{msec}$ (Fig. $2 B$ ); the mean coupling coefficient for action potentials in these pairs was $0.007 \pm 0.002$. However, in most pairs in which electrical coupling was clearly evident for relatively slow signals, action potential-evoked events were not visible; only six pairs in both rats and mice had visible spikelets ( $n=39$ coupled pairs). Neurons of the TRN readily generated low-threshold spikes and spike bursts after hyperpolarization (Fig. 2A) (Bal and McCormick, 1993). The relatively slow envelope of depolarization underlying each low-threshold burst evoked a depolarization in coupled postsynaptic neurons, with a magnitude well predicted by the low-frequency coupling coefficient of the pair (Fig. 2C); fast action potentials generated much smaller postsynaptic events proportionally. In another TRN pair (data not shown), which had a coupling coefficient of 0.03 (i.e., near the population average), the $10 \mathrm{mV}$ envelopes of low-threshold spikes evoked postsynaptic depolarizations of $\sim 320 \mu \mathrm{V}$; fast action potentials did not generate measurable postsynaptic events in this pair. To investigate the frequency dependence of coupling more systematically, subthreshold sinusoidal currents were injected into single cells while recording the induced voltage deflections in those cells and the cells coupled to them. The attenuation of the signals recorded in the noninjected neurons increased rapidly at stimulus frequencies $\geq 10 \mathrm{~Hz}$ (Fig. 3A,B).

\section{Electrical synapses can regulate firing patterns}

Electrical coupling was strong enough for the activity of one TRN cell to influence the firing patterns of another. This could be demonstrated in several ways. Figure $4 A$ shows recordings from a cell pair with a moderate coupling coefficient of 0.04 . When cell 1 was depolarized with 600 msec steps of $100 \mathrm{pA}$, it generated a train of action potentials (left traces). When cell 1 received the same stimulus but cell 2 concurrently received a $-300 \mathrm{pA}$ current step, both the duration of spiking and its rate were decreased in cell 1 (right traces). In addition, an electrical synapse could sometimes synchronize the action potentials of two simultaneously firing neurons. The cell pair shown in $B$ was strongly coupled. Application of simultaneous current stimuli evoked tonic firing in each cell. The cross-correlogram from the spiking in this pair has a strong peak centered on $0 \mathrm{msec}$, with a half-width of only $4 \mathrm{msec}$ $(C)$, indicating that the firing patterns of the cells were closely synchronized. This form of spike synchrony could be demonstrated only in the most strongly coupled pairs (i.e., coupling coefficients $\sim 0.1$ ).

Relatively low-frequency fluctuations of membrane potential were particularly effective at entraining the firing of coupled neurons. Figure $5 A$ shows data from a pair in which steady depolarizing current was injected to hold cell 2 close to the spiking threshold. When sinusoidal stimuli $(1 \mathrm{~Hz})$ sufficient to generate one spike per cycle were applied to cell 1, the spiking of cell 2 was entrained to the stimulus as well, at two spikes per cycle. Electrical coupling could also switch TRN cells between bursting and tonically spiking modes. Sinusoidal $(1 \mathrm{~Hz})$ current stimuli were first applied to cell 1 only (Fig. 5B) and adjusted so that a low-threshold burst fired near the peak of each stimulus cycle. Next, similar sinusoidal stimuli with the same phase were applied to both cells. The in-phase stimuli, interacting through the electrical synapse, reinforced the spiking of cell 1 and forced it to generate a burst plus two tonic spikes on each cycle. On the other hand, when the sinusoidal stimuli to the two cells were subsequently switched to anti-phase, the bursting in both cells was suppressed, and each fired only one or two spikes at the peak of each cycle. 


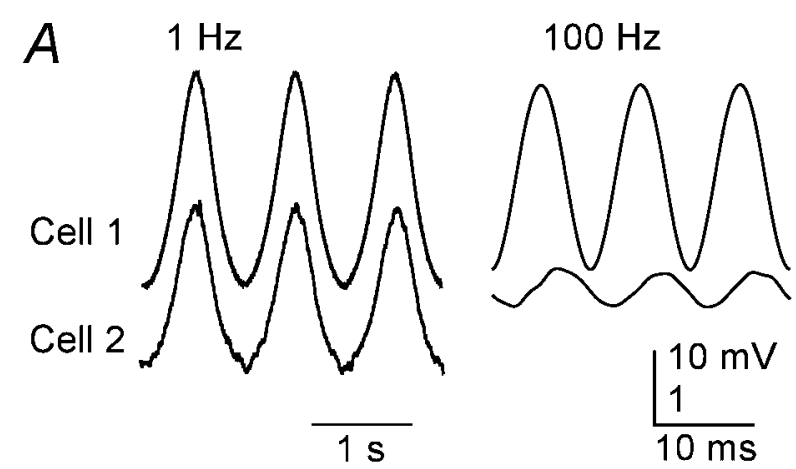

$B$

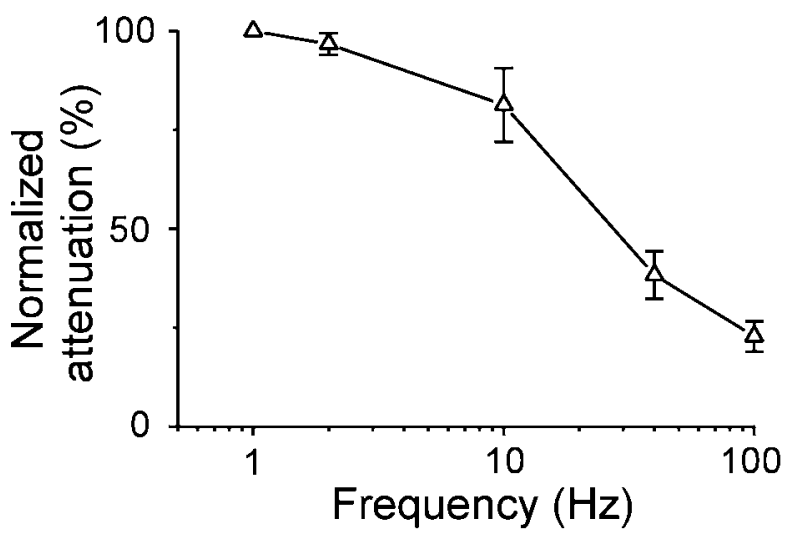

Figure 3. Frequency dependence of signal transfer between coupled neurons. $A$, Subthreshold sinusoidal currents were injected into one cell of a coupled pair, and membrane voltage deflections were recorded from the injected cell (top traces) and the cell coupled to it (bottom traces). Stimulus frequencies were $1 \mathrm{~Hz}$ (left traces) and $100 \mathrm{~Hz}$ (right traces). Note the differences in voltage gain between the traces of cell 1 (low gain) and cell 2 (high gain). $B$, Attenuation of sinusoidal signals across electrical synapses as a function of signal frequency. Data were obtained as described in $A$, and attenuation was defined as the ratio of peak-to-peak amplitudes in the noninjected compared with the injected cell, normalized to the 1 $\mathrm{Hz}$ attenuation and expressed as a percentage. Data points are the means \pm SEM of measurements from four neuron pairs.

\section{Electrical synapses in the TRN require $\mathrm{Cx} 36$}

Cx36 appears to be the predominant type of connexin expressed in central neurons (Condorelli et al., 1998; Rash et al., 2000; Venance et al., 2000). We tested the importance of Cx36 for electrical synapses between TRN neurons by studying WT and littermate mice that were homozygous for a null mutation of the Cx36 gene (KO mice). KO mice were constructed so that histochemical reporters were expressed in place of the $\mathrm{Cx} 36$ protein (Deans et al., 2001). The thalamic expression pattern of one reporter, $\beta$-galactosidase $(\beta$-gal), is shown in a $200-\mu$ m-thick vibratome section that was cut in the same oblique plane as the slices used for electrophysiology (Fig. 6A). Staining was very strong throughout the TRN, but it was notably sparse or absent in the relay nuclei of the dorsal thalamus. In this example, the reaction was strongly developed to reveal staining within relay nuclei. As a result, cellular detail in the TRN is obscured by the signal intensity. To reveal the cellular distribution of staining, 14- $\mu \mathrm{m}$-thick frozen sections were prepared, and the timing of the histochemical reaction was optimized for the TRN. As shown in Figure $6 B$, intense staining is evident, but it is restricted to a subset of TRN cell bodies. A substantial number of cells are completely devoid of the reaction product. Double labeling in
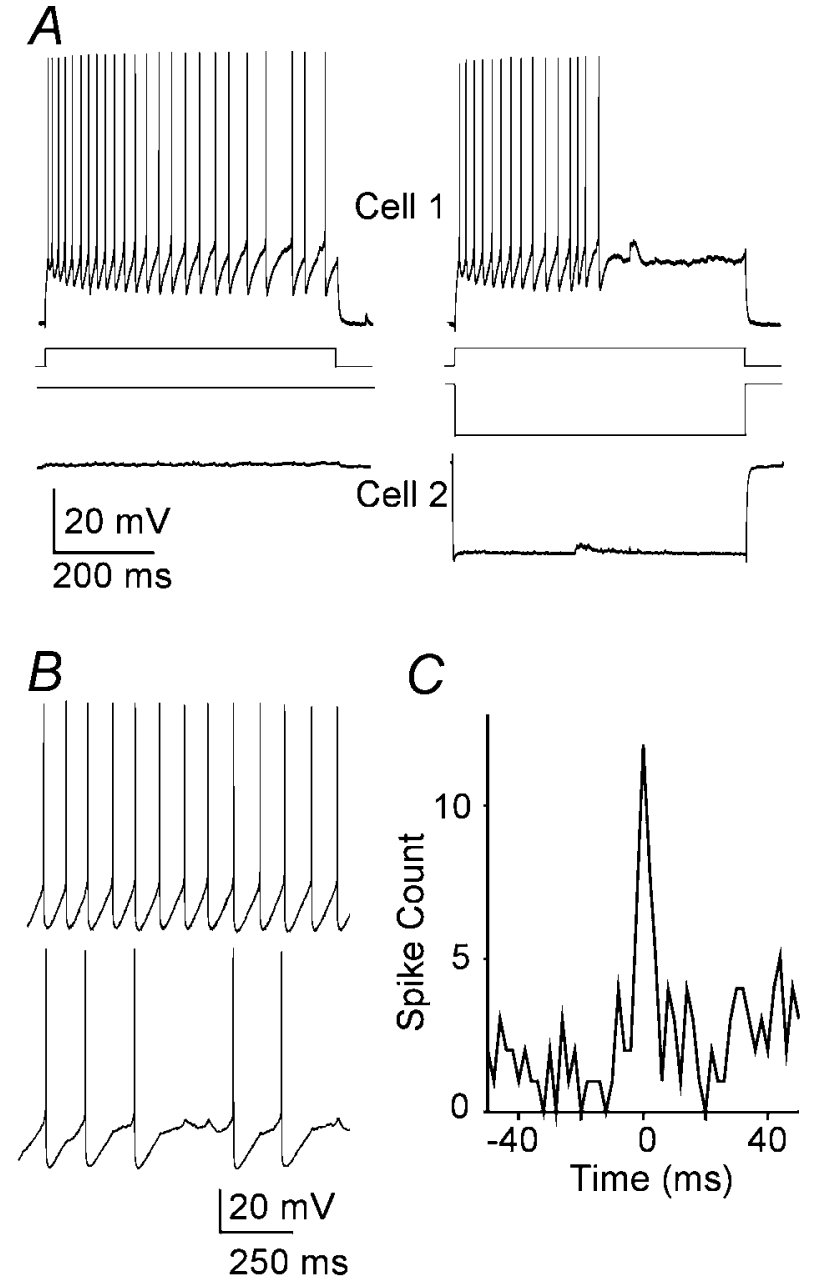

Figure 4. Electrical synapses can regulate spiking. A, Simultaneous recordings from a coupled TRN cell pair. Traces on the left show repetitive firing in cell 1 as it received a $100 \mathrm{pA}$ pulse of depolarizing current; cell 2 received no current. Traces on the right show how a hyperpolarizing current step of $-300 \mathrm{pA}$ delivered to cell 2 reduced the duration and frequency of spiking induced by the same $100 \mathrm{pA}$ stimulus to cell $1 . B$, Simultaneous current steps applied to a coupled pair (coupling coefficient of 0.1 ) evoked repetitive firing in both. Note the small spikelets in cell 2 during intervals of spike silence; each spikelet coincided with a spike in cell 1. $C$, Cross-correlogram of the spiking in the pair shown in $B$ shows a sharp, narrow peak centered on 0 msec.

companion sections for $\beta$-gal and for parvalbumin immunoreactivity (data not shown) confirmed that marker expression is abundant in some TRN neurons but absent in others. A restriction in Cx36 expression could explain the relatively low incidence of coupling between neurons in the TRN (31\%) compared with specific inhibitory interneurons in somatosensory cortex $(>60 \%)$ (Gibson et al., 1999; Deans et al., 2001). It is possible that, in the TRN, as in neocortex, inhibitory neurons are not homogeneous and that electrical synapses are restricted to some undefined neuronal subtype.

Paired recordings from TRN neurons of WT and heterozygous mice revealed that electrical coupling and other electrophysiological properties were very similar to those of TRN neurons from rats. Electrical coupling occurred in $32 \%$ of tested pairs (11 of 34 pairs; two of four of these pairs were in heterozygotes) (Fig. 6C, left). The mean coupling coefficient between coupled mouse pairs was $0.032 \pm 0.03$ (range, 0.01-0.13). In contrast, electrical cou- 


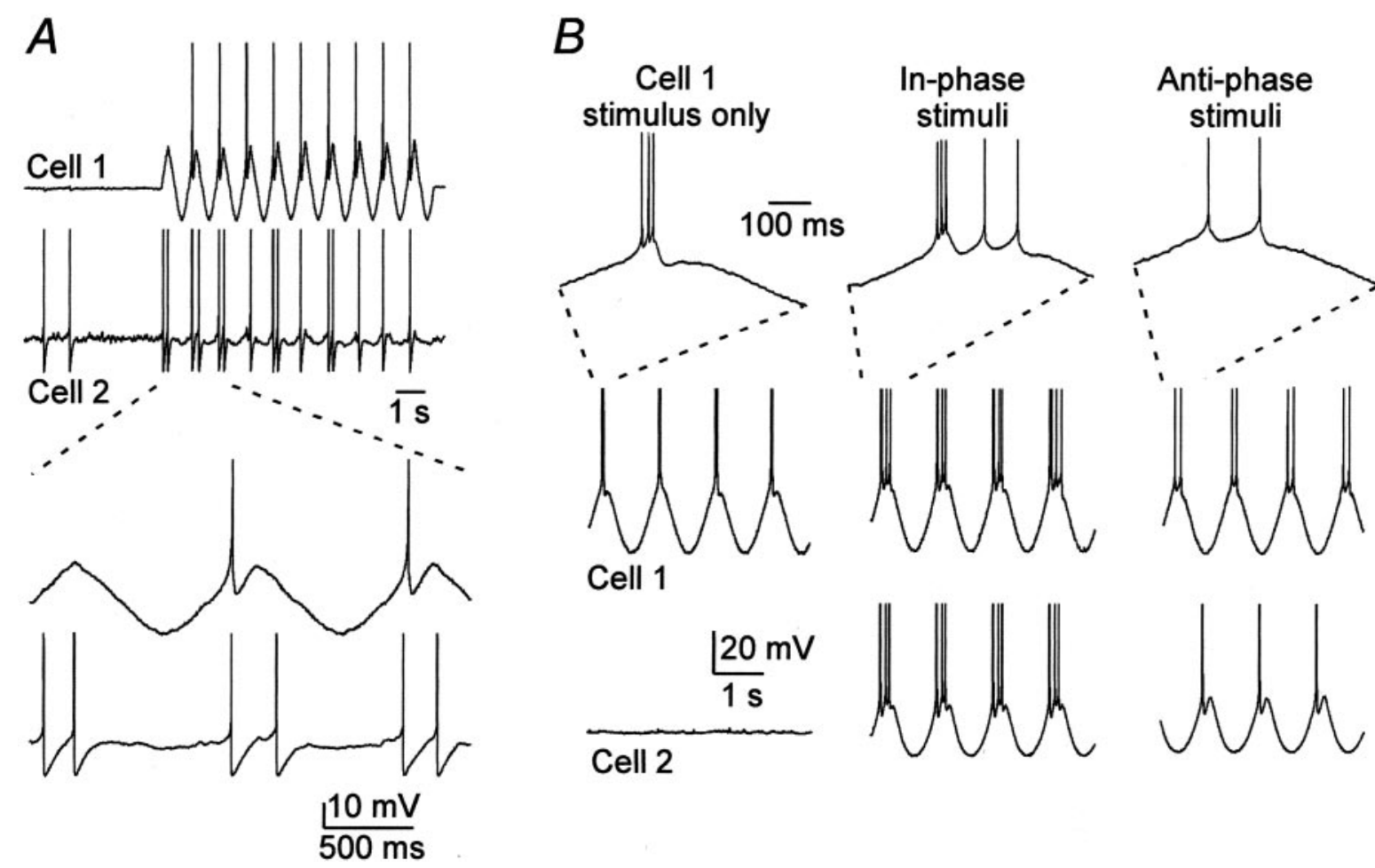

Figure 5. Modulation of spiking patterns mediated by electrical synapses. A, A sine wave current stimulus (1 Hz) was applied to cell 1 , with the amplitude adjusted to generate one spike per cycle. Cell 2 , which was electrically coupled to cell 1 , was depolarized with steady current to near threshold. Sine wave stimuli to cell 1 induced entrained spikes in cell 2 . The traces below show expansion of the traces above. Spikes in these panels are truncated. $B$, In a different pair of electrically coupled cells (coupling coefficient of 0.04), a $1 \mathrm{~Hz}$ sine wave stimulus to cell 1 induced firing of a single burst of spikes on each cycle (left). When both cells were stimulated with similar currents in-phase, cell 1 generated a burst plus two tonic spikes on each cycle (middle). When the same stimuli were shifted to anti-phase (right), cell 1 fired only two tonic spikes per cycle, and cell 2 fired a single spike per cycle. The top row shows expanded regions of recordings from cell 1, as indicated. Spike amplitudes have been truncated in all traces.

pling between TRN cells in $\mathrm{KO}$ tissue was all but absent (Fig. $6 C$, right). Only one of 38 pairs had measurable coupling, and that single coupled KO pair had an exceptionally low coupling coefficient $(\sim 0.002)$. Thus, TRN neurons from WT mice exhibited significantly more electrical coupling than the neurons of $\mathrm{KO}$ mice ( $p<0.001$; Fisher's exact test). Neither the input resistance $(\mathrm{WT}, 130 \pm 40 \mathrm{M} \Omega, n=46 ; \mathrm{KO}, 157 \pm 104 \mathrm{M} \Omega, n=85)$ nor the membrane time constant $(\mathrm{WT}, 10.3 \pm 3.4 \mathrm{msec}$; KO. $9.9 \pm 5.4$ $\mathrm{msec}$ ) of TRN cells varied with genotype. Intrinsic firing patterns of WT and KO neurons were not obviously different. These results suggest that virtually all electrical coupling between TRN neurons requires gap junctions containing Cx36.

\section{DISCUSSION}

\section{Electrical synapses between TRN neurons}

Our central conclusion is that many of the neurons in the TRN of rodents are interconnected by electrical synapses. At least one author speculated as early as the 1960s that electrical synapses might play a role in thalamic circuitry (Bennett, 1966), but the possibility was never given much credence nor had it been tested experimentally. Our most direct evidence comes from paired recordings of TRN neurons: changes of the transmembrane potential induced in one cell cause appropriate changes of potential in the adjacent cell. The properties of these electrical interactions are similar to most electrical synapses that have been studied in vertebrate nervous systems (Bennett, 1977; Galarreta and Hestrin, 2001): (1) coupling is symmetric, and current passes equally well in both directions; (2) there is no obvious rapid gating of the coupling conductance that depends on transjunctional voltage; (3) electrical signals are attenuated and low-pass filtered as they pass from the first cell to the second cell; and (4) coupling depends on the expression of a connexin protein. No other known form of electrical interaction between neurons is consistent with all of these properties.

Gap junctions are the morphological hallmark of electrical synapses (Bennett, 1977), but they are often small and are notoriously difficult to detect by transmission electron microscopy. The literature on the ultrastructure of gap junctions seems to lack any description of them between neurons of the TRN (Deschenes et al., 1985; Ohara and Lieberman, 1985; Ohara, 1988; Liu and Jones, 1999). In the neocortex, in which electrical synapses between GABAergic neurons are very common (Galarreta and Hestrin, 1999; Gibson et al., 1999) and for which innumerable ultrastructural studies have been done, descriptions of gap junctions have nevertheless been quite rare (Sloper and Powell, 1978; Tamas et al., 2000).

Surprisingly, we never detected chemical synaptic interactions in our TRN paired-cell recordings. It is unlikely that technical artifacts obscured them, because strong extracellular stimuli evoked IPSPs in single TRN cells. We frequently observed unitary IPSPs when using the same paired-cell recording methods in the neocortex (Gibson et al., 1999; Deans et al., 2001). Indeed, Zhang et al. (1997) described shock-evoked, as well as miniature IPSCs, in TRN cells of rodents; IPSPs can also be triggered in the cells of the ferret perigeniculate nucleus (which is part of the TRN) by applying glutamate to neighboring cells (Sanchez-Vives 

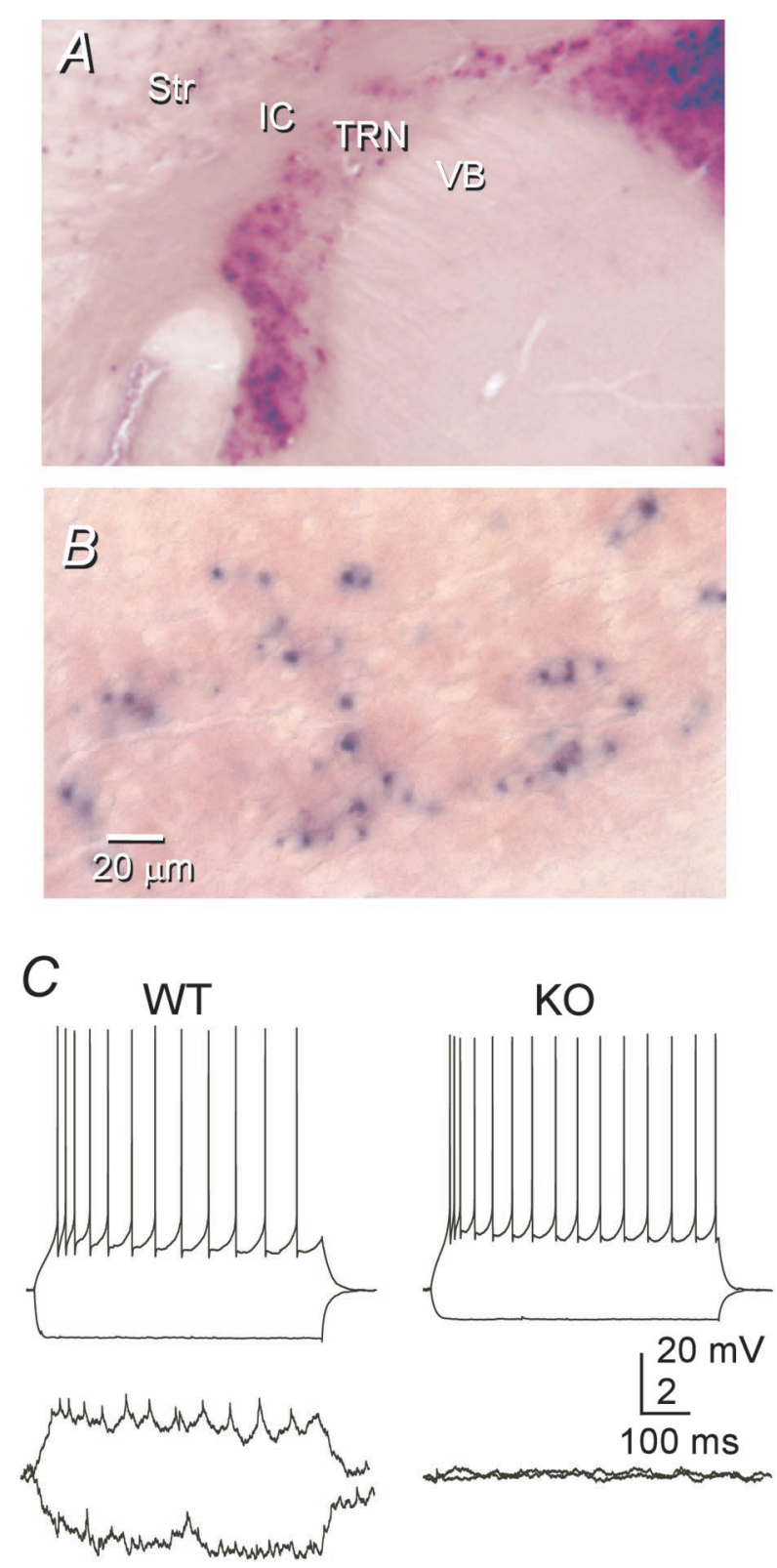

Figure 6. Electrical synapses in the TRN depend on Cx36. $A, \beta$-gal histochemistry of a section from a Cx36 KO mouse shows strong staining in the TRN but very weak staining in VB. The section was cut in the oblique plane used for electrophysiology (see Materials and Methods), and the reaction was strongly developed in an attempt to reveal staining in VB. $B$, Higher-power view of $\beta$-gal-reacted TRN, showing that some neurons stain strongly, whereas others are apparently unstained. In this case, the section was cut in the coronal plane, and the reaction time was optimized for the TRN. $C$, Moderate electrical coupling between a representative pair of TRN cells from a WT mouse (left); coupling was absent from almost all pairs of TRN cells from KO mice (right).

et al., 1997). There are at least two hypotheses with regard to why we did not observe paired-cell IPSPs. First, it may be that TRN neurons make very sparse connections with each other. This is consistent with the report that the size of spontaneous and miniature IPSCs in the cells of TRN and ventrobasal nucleus (VB) are similar, yet the peak amplitude of evoked IPSCs is four times larger in VB cells compared with TRN cells when using equivalent stimuli (Zhang et al., 1997). Second, it is possible that the probability of neurotransmitter release is very low at intra-

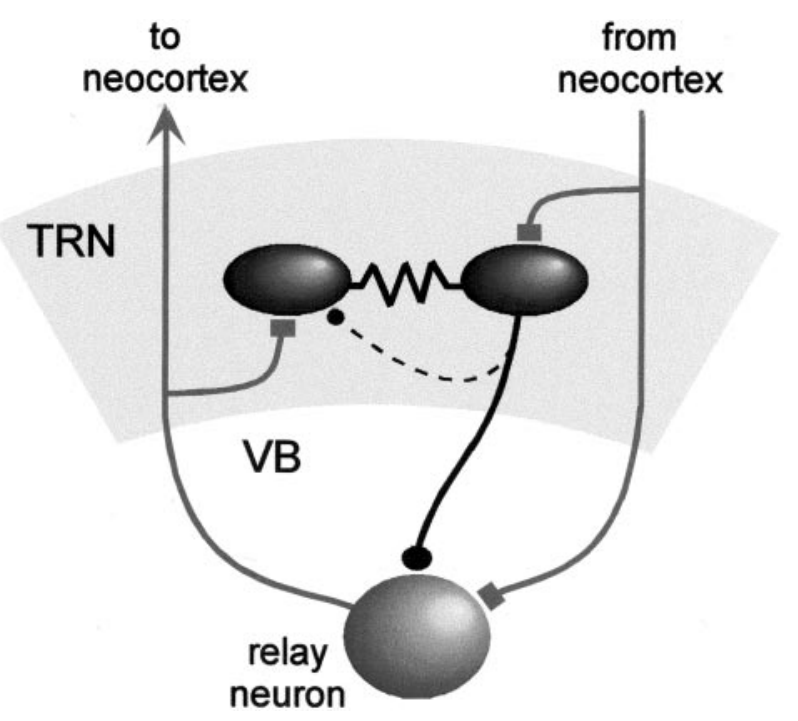

Figure 7. Synaptic circuitry of the TRN. Rectangular terminals, Excitatory chemical synapses; circular terminals, inhibitory chemical synapses; zigzagged lines, electrical synapses. The dashed line representing the intraTRN chemical synaptic connection indicates uncertainty about its structural basis.

TRN synapses; consistent with this, the frequency of miniature IPSCs was much smaller in TRN than in VB neurons (Zhang et al., 1997). Our limited testing protocol may have missed synaptic events of low probability. Both sparse connections and lowrelease probability are consistent with the very large stimulus currents we needed to evoke IPSPs. Anatomical results favor the hypothesis of sparse connections, because relatively small numbers of symmetric (Ohara, 1988) and GABA-immunoreactive (Liu and Jones, 1999) axosomatic and axodendritic synapses are observed within the TRN. It appears that intrinsic axonal arbors of rat TRN are short and spare (Cox et al., 1996; Liu and Jones, 1999) or, indeed, absent entirely (Pinault et al., 1995; Pinault and Deschenes, 1998). Some GABAergic synapses onto TRN cells also arise from extrinsic sources (Ohara and Lieberman, 1985; De Biasi et al., 1988), which could be activated with extracellular stimuli but would not be evident in paired-cell recordings. In a study that combined single-cell reconstruction with serial section electron microscopy, Pinault et al. (1997) suggested that dendrodendritic synapses might be the sole type of GABAergic interconnection in the TRN of rodents. However, not all studies have supported this conclusion (Ohara and Lieberman, 1985; Liu and Jones, 1999).

It seems very likely that inhibitory synaptic connections within the TRN exist, but additional studies will be needed to resolve their properties. Our recordings show that at least a subset of TRN cells are also coupled by electrical synapses. The circuit diagram in Figure 7 illustrates the general pattern of chemical and electrical synaptic connections within the TRN.

\section{Role of Cx36 in the TRN}

We found that mice with a null mutation for $C x 36$ were nearly devoid of electrical synapses in the TRN. This suggests that Cx36 is an essential component of functional gap junctions between most TRN neurons. Cx36 may also be sufficient for this purpose, because it is the only one of $>16$ connexin subtypes that is preferentially expressed by central neurons (Condorelli et al., 1998). Studies that combine freeze fracture electron microscopy 
with immunocytochemistry have concluded that $\mathrm{Cx} 36$, but not $\mathrm{Cx} 43$ and $\mathrm{Cx} 32$, is found within gap junctions that interconnect neurons in a variety of mammalian brain regions (Rash et al., 2000, 2001). The anatomical localization of Cx36 is also consistent with our physiological results. The mRNA for Cx36 is densely expressed in the TRN, in stark contrast to most thalamic relay nuclei, which are "completely devoid of hybridization grains" (Condorelli et al., 2000). Our $\beta$-gal staining patterns are similar to these in situ hybridization patterns (Fig. 6A). The restricted expression of $\beta$-gal among TRN cells is consistent with the relatively modest incidence of electrical coupling; it suggests that electrical synapses selectively interconnect subsets of TRN neurons.

The intercellular channels formed by Cx36 have interesting properties that distinguish them from other connexins. Cx36 channels have the weakest voltage-dependent gating and the smallest single-channel conductance of any tested connexin; they are only slightly permeable to some organic dyes that permeate other connexin channels easily (Srinivas et al., 1999; Teubner et al., 2000). This is consistent with the absence of dye coupling between electrically coupled TRN cells (in this study) and neocortical interneurons (Gibson et al., 1999).

Recent studies have shown that GABAergic neurons of the neocortex (Galarreta and Hestrin, 1999; Gibson et al., 1999; Tamas et al., 2000) and hippocampus (Venance et al., 2000) are also electrically coupled and that the coupling is severely deficient in Cx36 KO mice (Deans et al., 2001; Hormuzdi et al., 2001). This raises the possibility that $\mathrm{Cx} 36$ expression is necessary for the large majority of electrical coupling between inhibitory neurons of the mammalian forebrain. Such molecular specificity should be very helpful for studies of the functional role of electrical synapses, because there are powerful methods potentially available to manipulate the timing and location of $\mathrm{Cx} 36$ expression patterns selectively.

\section{Functions of electrical synapses in the TRN}

Understanding the role of electrical synapses in the TRN is complicated by uncertainty about the functions of the TRN itself. This nucleus has been implicated in, among other things, mechanisms of sensory processing (Yingling and Skinner, 1976; Lee et al., 1994; Hartings et al., 2000), attention (Crick, 1984; Guillery et al., 1998), the generation of synchronous, rhythmic activity during slow-wave sleep and certain seizure states (Steriade et al., 1987; Bal and McCormick, 1993; Kim et al., 1995; Avanzini et al., 2000), and the development of connections between the thalamus and the neocortex (Mitrofanis and Guillery, 1993). These diverse functions undoubtedly require myriad cellular mechanisms, but one feature that could be common to all of them is some degree of synchronized neuronal activity. This converges nicely with the well known ability of electrical synapses to synchronize neurons across a range of temporal scales (Bennett, 1966, 1977). Our studies of interactions between paired neurons show clearly that electrical synapses can synchronize neurons in the TRN. Our results imply that the relatively strong filtering properties of electrical connections between TRN cells favor the synchronization of low-frequency events, such as low-threshold calcium spikes and even slower fluctuations, and preclude spike-to-spike synchrony in all but the most strongly coupled groups of neurons. In comparison, the electrical synapses between neocortical interneurons are frequently able to mediate a temporally close $( \pm 1 \mathrm{msec})$ synchrony of spikes (Galarreta and Hestrin, 1999; Gibson et al., 1999).
Studies of synchrony in the TRN have emphasized the roles of chemical synapses. For example, spindle rhythms apparently arise from an alternation between excitatory cortical and thalamic inputs onto TRN cells on the one hand, and inhibitory TRN inputs back to thalamic relay and cortical cells on the other (Bal et al., 1995a,b; Cox et al., 1997; Sanchez-Vives and McCormick, 1997). The GABAergic synaptic connections within the TRN of rodents may mediate sustained, rhythmic, propagating activity during sleep (Bazhenov et al., 1999), but there is also evidence that they serve to desynchronize certain forms of rhythmic activity and restrict them spatially (Huntsman et al., 1999; Sohal et al., 2000). However, all of these studies assume strong and extensive local chemical connections, which is not consistent with our findings. Studies in ferret perigeniculate nucleus also support the role of TRN cells in desynchronizing spindle oscillations (Bal et al., 1995b; Sanchez-Vives et al., 1997). Perhaps within the TRN network, electrical and chemical synapses serve opposing roles, with chemical synapses desynchronizing relatively high-frequency activity (e.g., 7-14 Hz sleep spindles) and electrical synapses synchronizing relatively low-frequency activity (e.g., $\leq 1 \mathrm{~Hz}$ delta rhythms), as they do in neocortex (Beierlein et al., 2000). Electrical coupling between TRN neurons may also be important during certain pathological states, especially seizures. For example, the $3 \mathrm{~Hz}$ paroxysms that characterize spike-wave seizures are accompanied by periodic, synchronized excitation of TRN neurons by corticothalamic synapses (Steriade and Contreras, 1995). The excited TRN neurons generate feedforward waves of inhibition in thalamic relay cells, synchronized, perhaps, by the influence of electrical synapses within the TRN.

\section{REFERENCES}

Avanzini G, Panzica F, de Curtis M (2000) The role of the thalamus in vigilance and epileptogenic mechanisms. Clin Neurophysiol 111 [Suppl 2]:S19-S26.

Bal T, McCormick DA (1993) Mechanisms of oscillatory activity in guinea-pig nucleus reticularis thalami in vitro: a mammalian pacemaker. J Physiol (Lond) 468:669-691.

Bal T, von Krosigk M, McCormick DA (1995a) Synaptic and membrane mechanisms underlying synchronized oscillations in the ferret lateral geniculate nucleus in vitro. J Physiol (Lond) 483:641-663.

Bal T, von Krosigk M, McCormick DA (1995b) Role of the ferret perigeniculate nucleus in the generation of synchronized oscillations in vitro. J Physiol (Lond) 483:665-685.

Bazhenov M, Timofeev I, Steriade M, Sejnowski TJ (1999) Selfsustained rhythmic activity in the thalamic reticular nucleus mediated by depolarizing $\mathrm{GABA}_{\mathrm{A}}$ receptor potentials. Nat Neurosci 2:168-174.

Beierlein M, Gibson JR, Connors BW (2000) An electrically coupled network of interneurons drives synchronized inhibition in neocortex. Nat Neurosci 3:904-910.

Bennett MVL (1966) A comparative study of neuronal synchronization. In: The thalamus (Purpura DP, Yahr MD, eds), pp 173-181. New York: Columbia UP.

Bennett MVL (1977) Electrical transmission: a functional analysis and comparison to chemical transmission. In: Handbook of physiology, Sec I, The nervous system, Vol I, Pt 1 (Brookhart JM, Mountcastle VB, eds), pp 357-416. Bethesda, MD: American Physiological Society.

Condorelli DF, Parenti R, Spinella F, Trovato Salinaro A, Belluardo N, Cardile V, Cicirata F (1998) Cloning of a new gap junction gene (Cx36) highly expressed in mammalian brain neurons. Eur J Neurosci 10:1202-1208.

Condorelli DF, Belluardo N, Trovato-Salinaro A, Mudo G (2000) Expression of Cx36 in mammalian neurons. Brain Res Rev 32:72-85.

Cox CL, Huguenard JR, Prince DA (1996) Heterogeneous axonal arborizations of rat thalamic reticular neurons in the ventrobasal nucleus. J Comp Neurol 366:416-430.

Cox CL, Huguenard JR, Prince DA (1997) Peptidergic modulation of intrathalamic circuit activity in vitro: actions of cholecystokinin. J Neurosci $17: 70-82$

Crick F (1984) Function of the thalamic reticular complex: the searchlight hypothesis. Proc Natl Acad Sci USA 81:4586-4590.

Deans MR, Gibson JR, Sellitto C, Connors BW, Paul DL (2001) Synchronous activity of inhibitory networks in neocortex requires electrical synapses containing connexin36. Neuron 31:477-485. 
De Biasi S, Frassoni C, Spreafico R (1988) The intrinsic organization of the ventroposterolateral nucleus and related reticular thalamic nucleus of the rat: a double-labeling ultrastructural investigation with gammaaminobutyric acid immunogold staining and lectin-conjugated horseradish peroxidase. Somatosens Res 5:187-203.

Deschenes M, Madariaga-Domich A, Steriade M (1985) Dendrodendritic synapses in the cat reticularis thalami nucleus: a structural basis for thalamic spindle synchronization. Brain Res 334:165-168.

Destexhe A, Contreras D, Sejnowski TJ, Steriade M (1994) A model of spindle rhythmicity in the isolated thalamic reticular nucleus. J Neurophysiol 72:803-818.

Galarreta M, Hestrin S (1999) A network of fast-spiking cells in the neocortex connected by electrical synapses. Nature 402:72-75.

Galarreta M, Hestrin S (2001) Electrical synapses between GABAreleasing interneurons. Nat Rev Neurosci 2:425-433.

Gibson JR, Beierlein M, Connors BW (1999) Two networks of electrically coupled inhibitory neurons in neocortex. Nature 402:75-79.

Guillery RW, Feig SL, Lozsadi DA (1998) Paying attention to the thalamic reticular nucleus. Trends Neurosci 21:28-32.

Hartings JA, Temereanca S, Simons DJ (2000) High responsiveness and direction sensitivity of neurons in the rat thalamic reticular nucleus to vibrissa deflections. J Neurophysiol 83:2791-2801.

Hormuzdi SG, Pais I, LeBeau FEN, Towers SK, Rozov A, Buhl EH, Whittington MA, Monyer H (2001) Impaired electrical signaling disrupts gamma frequency oscillations in connexin36 deficient mice. Neuron 31:487-495.

Houser CR, Vaughn JE, Barber RP, Roberts E (1980) GABA neurons are the major cell type of the nucleus reticularis thalami. Brain Res 200:341-354.

Huntsman MM, Porcello DM, Homanics GE, DeLorey TM, Huguenard JR (1999) Reciprocal inhibitory connections and network synchrony in the mammalian thalamus. Science 283:541-543.

Kim U, Bal T, McCormick DA (1995) Spindle waves are propagating synchronized oscillations in the ferret LGNd in vitro. J Neurophysiol 74:1301-1323.

Kim U, Sanchez-Vives MV, McCormick DA (1997) Functional dynamics of GABAergic inhibition in the thalamus. Science 278:130-134.

Lee SM, Friedberg MH, Ebner FF (1994) The role of GABA-mediated inhibition in the rat ventral posterior medial thalamus. I. Assessment of receptive field changes following thalamic reticular nucleus lesions. J Neurophysiol 71:1702-1715.

Liu XB, Jones EG (1999) Predominance of corticothalamic synaptic inputs to thalamic reticular nucleus neurons in the rat. J Comp Neurol 414:67-79.

Mitrofanis J, Guillery RW (1993) New views of the thalamic reticular nucleus in the adult and the developing brain. Trends Neurosci 16:240-245.

Ohara PT (1988) Synaptic organization of the thalamic reticular nucleus. J Electron Microsc Tech 10:283-292.

Ohara PT, Lieberman AR (1985) The thalamic reticular nucleus of the adult rat: experimental anatomical studies. J Neurocytol 14:365-411.

Pinault D, Deschenes M (1998) Projection and innervation patterns of individual thalamic reticular axons in the thalamus of the adult rat: a three-dimensional, graphic, and morphometric analysis. J Comp Neurol 391:180-203.

Pinault D, Bourassa J, Deschenes M (1995) The axonal arborization of single thalamic reticular neurons in the somatosensory thalamus of the rat. Eur J Neurosci 7:31-40.

Pinault D, Smith Y, Deschenes M (1997) Dendrodendritic and axoaxonic synapses in the thalamic reticular nucleus of the adult rat. J Neurosci 17:3215-3233.

Rash JE, Staines WA, Yasumura T, Patel D, Furman CS, Stelmack GL, Nagy JI (2000) Immunogold evidence that neuronal gap junctions in adult rat brain and spinal cord contain connexin-36 but not connexin-32 or connexin-43. Proc Natl Acad Sci USA 97:7573-7578.
Rash JE, Yasumura T, Dudek FE, Nagy JI (2001) Cell-specific expression of connexins and evidence of restricted gap junctional coupling between glial cells and between neurons. J Neurosci 21:1983-2000.

Sanchez-Vives MV, McCormick DA (1997) Functional properties of perigeniculate inhibition of dorsal lateral geniculate nucleus thalamocortical neurons in vitro. J Neurosci 17:8880-8893.

Sanchez-Vives MV, Bal T, McCormick DA (1997) Inhibitory interactions between perigeniculate GABAergic neurons. J Neurosci 17:8894-8908.

Scheibel ME, Scheibel AB (1966) The organization of the nucleus reticularis thalami: a Golgi study. Brain Res 1:43-62.

Sloper JJ, Powell TP (1978) Gap junctions between dendrites and somata of neurons in the primate sensori-motor cortex. Proc R Soc Lond B Biol Sci 203:39-47.

Sohal VS, Huntsman MM, Huguenard JR (2000) Reciprocal inhibitory connections regulate the spatiotemporal properties of intrathalamic oscillations. J Neurosci 20:1735-1745.

Spreafico R, Battaglia G, Frassoni C (1991) The reticular thalamic nucleus (RTN) of the rat: cytoarchitectural, Golgi, immunocytochemical, and horseradish peroxidase study. J Comp Neurol 304:478-490.

Srinivas M, Rozental R, Kojima T, Dermietzel R, Mehler M, Condorelli DF, Kessler JA, Spray DC (1999) Functional properties of channels formed by the neuronal gap junction protein connexin36. J Neurosci 19:9848-9855.

Steriade M, Contreras D (1995) Relations between cortical and thalamic cellular events during transition from sleep patterns to paroxysmal activity. J Neurosci 15:623-642.

Steriade M, Domich L, Oakson G, Deschenes M (1987) The deafferented reticular thalamic nucleus generates spindle rhythmicity. J Neurophysiol 57:260-273.

Steriade M, Jones EG, McCormick DA (1997) Thalamus, Vol 1, Organisation and function, pp 31-174. Amsterdam: Elsevier Science.

Tamas G, Buhl EH, Lorincz A, Somogyi P (2000) Proximally targeted GABAergic synapses and gap junctions synchronize cortical interneurons. Nat Neurosci 3:366-371.

Teubner B, Degen J, Sohl G, Guldenagel M, Bukauskas FF, Trexler EB, Verselis VK, De Zeeuw CI, Lee CG, Kozak CA, Petrasch-Parwez E, Dermietzel R, Willecke K (2000) Functional expression of the murine connexin36 gene coding for a neuron-specific gap junctional protein. $\mathrm{J}$ Membr Biol 176:249-262.

Ulrich D, Huguenard JR (1996) GABA $_{B}$ receptor-mediated responses in GABAergic projection neurones of rat nucleus reticularis thalami in vitro. J Physiol (Lond) 493:845-854.

Venance L, Rozov A, Blatow M, Burnashev N, Feldmeyer D, Monyer H (2000) Connexin expression in electrically coupled postnatal rat brain neurons. Proc Natl Acad Sci USA 97:10260-10265.

Wang XJ, Rinzel J (1993) Spindle rhythmicity in the reticularis thalami nucleus: synchronization among mutually inhibitory neurons. Neuroscience 53:899-904.

Warren RA, Agmon A, Jones EG (1994) Oscillatory synaptic interactions between ventroposterior and reticular neurons in mouse thalamus in vitro. J Neurophysiol 72:1993-2003.

Williamson AM, Ohara PT, Ralston DD, Milroy AM, Ralston HJ (1994) Analysis of gamma-aminobutyric acidergic synaptic contacts in the thalamic reticular nucleus of the monkey. J Comp Neurol 349:182-192.

Yen CT, Conley M, Hendry SH, Jones EG (1985) The morphology of physiologically identified GABAergic neurons in the somatic sensory part of the thalamic reticular nucleus in the cat. $J$ Neurosc 5:2254-2268

Yingling CD, Skinner JE (1976) Selective regulation of thalamic sensory relay nuclei by nucleus reticularis thalami. Electroencephalogr Clin Neurophysiol 41:476-482.

Zhang SJ, Huguenard JR, Prince DA (1997) GABA $_{\mathrm{A}}$ receptormediated $\mathrm{Cl}^{-}$currents in rat thalamic reticular and relay neurons. J Neurophysiol 78:2280-2286. 